\title{
Evaluation of Political News Reportage in Nigeria's Vanguard and The Guardian Newspapers
}

\author{
Ndoma J. Brown'1, Israel W. Udomisor ${ }^{2}$ \\ ${ }^{1}$ Department of Mass Communication, Cross River University of Technology, Calabar, Nigeria \\ ${ }^{2}$ Department of Mass Communication, University of Maiduguri, Maiduguri, Nigeria \\ Email: ndomabrown@gmail.com
}

Received 3 February 2015; accepted 27 February 2015; published 2 March 2015

Copyright (C) 2015 by authors and Scientific Research Publishing Inc.

This work is licensed under the Creative Commons Attribution International License (CC BY). http://creativecommons.org/licenses/by/4.0/

(c) (i) Open Access

\section{Abstract}

This study was conducted to assess how political issues were treated in Nigeria's newspapers, by assessing: the ratio of political news to the other subject matters, the readers' interest given to political stories and the level of prominence attached to these stories by the way of placement and importance. Content analysis was used to gather data, and the study sample was derived through stratified sampling method. A total of 36 daily publications of the two newspapers were content analyzed from a pool of sample drawn through stratified random sampling technique from issues of the newspapers published within the three months period-April to June, 2013. The data from these newspapers were analyzed using independent t-test statistical technique. Findings showed that political issues were not given adequate attention in the two newspapers, and were mostly tailored towards government's interests. The recommendations among others were that the Nigerian newspapers, in general, should render vivid and unbiased reportage of political issues, as well as scale-up political content in publications as a way of consolidating political consciousness in Nigeria.

\section{Keywords}

News, Frequency, Placement, Prominence, Proximity and Interest

\section{Introduction}

Communication is elemental to human existence; no human association can cohere without communication. In fact, one cannot but communicate, for even the most sublime acts of restraint or withdrawals are loud messages 
conveying readable meaning to the receiver. By definition, "Communication is seen as the sharing of meaning, messages, ideas, thoughts, information and experiences with one's self, with another individual, with a group or with the mass of people," (Bledcom, 2014, http://www.bledcom.com/). Inherent in that definition is the fact that communication is continuous and dynamic; therefore, the continuous study of mass communication and its measurable impact on people and societies becomes expedient. But as we attempt to study communication, we realize that mass communication is driven by a structured industry called "the press". The press plays the key role of midwife in the facilitation of communication in the society. This role is pivotal to the sustainability of society as it facilitates economic, cultural, social and political growth through information dissemination, education, entertainment and mobilization. Little wonder the press has been tagged the "fourth estate" in recognition of its stately duty of being a link between government and the governed and for its watchdog function on the society. Similarly, the newspaper (the colossal agent of the press) is the oldest medium of mass communication with its existence traceable to the $17^{\text {th }}$ century. Hynds as cited in Daramola (2003) avers that: “At the beginning, the newspaper was society's primary instrument of mass communication and till today the log book of human affairs than any other means of communication”( p.120).

In Nigeria, the first newspaper Iwe Irohin was published in Abeokuta in 1859 by Reverend Henry Townsend, an English Missionary of the Anglican Mission. Since then the country has witnessed phenomenal growth in the newspaper sector so much so that it has become something of a tool in stating and defending ideology by individuals and political entities. This is perhaps due to its accessibility and portability over other media (Brown, 2013), even though the reading culture of an average Nigerian has greatly dropped owing to various internal and circular excuses (Baran in Brown, 2014). Despite the transcendental advancement of electronic media, the newspaper is a popular channel of mass communication, and an integral part of Nigeria's political consciousness. Given these, therefore, this study attempts to evaluate how Nigeria's Vanguard and The Guardian cover and report political issues.

On the contribution of this understudied aspect of news to academic database, Ekwo (2014) opines that the new influence gained by the masses in a converged media environment can be translated into political energy thereby precipitating a new political culture where power truly belongs to the people. This mindset also crystallizes Skinner, Compton and Gasher's (2005) conception of participatory democracy in which citizens are actively engaged in not just putting representatives in power but also involved in setting agenda and shaping policy alternatives, (Ekwo, 2014, http://cmpimedia.org). Similarly, we strongly believe that the principle behind every accepted news style is embedded in our culturally-based maxim of news reportage. Henceforth, this study will sharpen and level the skills and techniques of both teachers and students in the journalistic practice of news writing.

\section{Literature Review}

Uzochukwu and Dunu (2010) posit that communication has been a vital catalyst in the process of socio-economic and political development. The authors further explained that communication has long been used in the promotion of good health practices since it constitutes a source of information through which people learn about the world around them. Sinha (1986) says that, apart from being an integral part of human and social life, communication has played a very important role in the acculturation process. Haque (1986) is of the opinion that news media are one of the principal channels for disseminating information about the political institutions and processes in modern societies. "Brookfield (1986) says that the mass media play a crucial role in framing our views of the world and the context within which we decide which issues and problems are significant in the political realm,” (Coe, 2014, http://www.coe.uga.edu/). News, as a vital commodity of the communication industry, stimulates an important increase in productivity in public administration, industry, agriculture and social services. News, according to Ghorpade (1986) helps in effective planning of all facets of our economic, political and social life.

News is the life blood of politics and for politics to grow and flow in the right directions; it must be infused with the right 'blood.' In this case, the right type of news for politics to experience growth and development should be basically considered in the interest of the society.

Journalists and politicians know that they cannot succeed without each other in their respective careers. Therefore, despite the conflicting relationship that may exist between them, they manage to maintain a relation- 
ship that would help them to use each other in achieving their professional goals. Blumler and Gurevitch (1981) state that while tension exist in press-politicians' relations, it calls for mutual co-operation for the good of the society. This is so because the media facilitate the exchange of information between policy making bodies which include politicians. In supporting this, Fico (1984) points out that legislations are heavy consumers of information supplied by the mass media and other sources such as interest groups, constituents, technical experts and colleagues. This is obvious because law makers and politicians are important sources of information and opinion that the mass media transmit to society. Stressing the reasons for press-politicians' relationship and why journalists should accord seriousness to news reporting, Fico (1984) further upholds that reporters are gate keepers to media access for public officials who are always seeking to reach broad audiences. Reporters, he says, are also important sources of information and feedback to politicians and government officials. Ghorpade (1986) also considers the "press as playing an influential role in a country’s political milieu,” (Nml, 2014,

http://nml.ru.ac.za/blog/guy-begger/). According to him, why readership of newspapers is known to grow higher during election years and that by emphasizing certain issues over others, the press plays agenda-setting roles among the educated elite in a society.

Haque cited in Udomisor (2002) observes that the news media devote a substantial part of their time and resources to covering politics. According to Haque (1986), the vicissitudes of parties, personnel changes, their rise and fall, the personality conflicts and bickering combined with the all pervasive government decisions and activities form the political process and institutions that the media must report on. It is therefore an established fact that among communication scholars in any media system whether democratic or socialist, politics and government constitute a major topic of coverage, despite the fact that ideological orientation and social structures may affect the nature of reportage in terms of central characters, issues and the manner of reporting by each medium.

In forestalling these challenges, Udomisor and Bwala (2010) had warned that the lopsidedness which may be experienced in the contents and coverage of politics will thwart developmental practice by the Nigerian print media, thereby floating bad appendices for media ownership. According to them, while government requires complete allegiance of the media organs to their policies of information dissemination, the private media owners and their newspapers tend to give undue priority to commercial matters for profit motives. This state of affairs in the coverage of politics by the Nigerian media has also been observed by other communication scholars. Therefore, it sounds illogical to think and most unrealistic to hope that the general imbalance in the level of political reporting by various print media houses in Nigeria will not affect the level of information distribution within the country.

To effectively understand the inherent contradiction in the political news reportage by the Nigerian print media, Soola (1995) clearly states that the Nigerian media industry has only been so pre-occupied in the acquisition of sophisticated modern communication technology hardware with a complete disregard to the operational communication, which received only a token attention. It should be noted that the development of the human variables in the operational aspects of the media rather than the impressive arrays of communication technologies would lead to the proper operation of the media for balanced news reportage. It is observed that in Nigeria not much consideration is given to the crucial role of the media choosers, message designers and producers, their training and skill as well as their knowledge of the socio-cultural and political context of the audiences.

The inherent contradiction in the news content and reportage in the print media system in Nigeria may be traced to Haque (1986) when he says that while the press system of developing nations may profess the libertarians or social responsibility, each of these systems encompass a philosophy involving belief in the nature of man and the nature of society and the state. In Nigeria, while this system may envisage vagueness, the press systems of this nation are not pure as her press systems combine elements from different systems in its operation.

\subsection{Aims and Objectives}

The aims and objectives of this study were as follows:

1) To examine how the print media in Nigeria report political issues.

2) To examine the rate at which political news is given prominence in the process of news coverage.

3) To examine the relevance of adequate political news report by newspapers.

4) To make relevant recommendations towards improving the rate of political news reportage by Nigeria's newspapers. 


\subsection{Significance of the Study}

This study becomes very important because it will enable the print media to re-assess their roles in bringing about political stability and development in the society. Politicians will find this study useful in re-examining their activities and behaviours in the political arena and how their relationship with the media affects the political stability of the nation.

The masses will be able to anticipate how the relationship between the media and the political class could lead to the manipulation of their consciousness away from truth and reality.

\section{Methodology}

The methods used to obtain data for analysis in this study were documentary survey and content analysis. Documentary survey was used to generate secondary data, mostly in the literature review for this study. Data were collected through visit to libraries to read books, journals and other literature materials available for the researchers. Content analysis was used to generate primary data for the benefit of this study. In these selected newspapers, Vanguard and The Guardian newspapers were selected from among newspapers published in Nigeria and used for analysis on the theme of the study. "Content analysis as a method is used for generating primary data for a study because it allows for an objective, systematic and qualitative description of communication content,” Berelson (1952: p. 18).

\subsection{Number of Newspapers Covered by the Study}

The total number of newspapers covered by the study consisted of all the newspapers published in the country by Vanguard, and The Guardian from April 1 to June 30, 2013. The total number of Vanguard and The Guardian newspapers published within this period is 180 . However, for practicability, only the political issues of these newspapers were used for the study.

\subsection{Criteria for Selecting the Newspapers}

Circulation: The selected newspapers had a circulation range of 100,000 - 500,000 copies per day.

Ownership: The newspapers were owned by private interests.

Coverage: The newspapers evaluated for this study could be seen at newsstands across the country.

Frequency of publication: The selected newspapers were dailies running from Sunday to Saturday. Going by the afore-stated criteria, Vanguard and The Guardian newspapers were selected for the study.

\subsection{Methods, Sampling Technique and Sample Size}

Data collected in the course of this study were analysed using independent t-test statistical technique. The coding for this study was done by the researchers and a statistician colleague. This ensured that an acceptable intercoder agreement, between two independent coders was achieved after some adjustments in the coding scheme had been made.

Stratified random sampling technique was used to select the sample for the study. The researchers used the systematic sampling method to arrive at the exact sample for the study. The stratified sampling technique, according to Wimmer and Dominick (2006) "ensures that a sample is drawn from a homogeneous subset of the population - that is, from a population that has similar characteristics; homogeneity in helping researchers to reduce sampling errors," (p. 87). Using the sampling technique, the researchers entered the data arbitrarily, selecting the newspapers at an interval of six issue dates.

There were 180 issues of the two newspapers during the study period of April to June, 2013. But issues of the newspapers to be analyzed had to be determined through an appropriate sample size. Wimmer and Dominick (2006) recommend a sampling rate of $10 \%$ or $20 \%$. The researchers chose a sampling rate of one out of six, representing $20 \%$ of the population in drawing the size, allowing both newspapers equal chance of being selected as representatives of the population, (p. 83). Systematic sampling was then used to arrive at the exact issue dates of the newspapers to be analyzed. Thus, from the sample population of 180, a sample size of 36 was reached after the researchers selected 18 issue dates to represent the population for each of the two newspapers. 
The following content areas of the two newspapers were analyzed: news, features, editorials, and cartoons. The researchers counted every political news story, editorial comment, feature article and cartoon as a unit each.

\subsection{Construction of Categories}

For coding purposes, the newspaper contents were operationally defined. The category system is used to classify factors affecting political awareness.

Story types: News, Editorials, Features, Cartoons.

Story placement: Front page, Back page, Inside page.

Readers' interest: Favourable (Positive), Unfavourable (Negative), Neutral.

Subjects covered: Government/Politics, Health/Welfare, Education/Technology/Art, Business/Economy, Agriculture, Crime/Violence, Religion/Morality, Sports/Entertainment, Others.

\subsection{Sources of Data Collection}

The data for this study were drawn from samples of Vanguard and The Guardian newspapers for a period of three months: April-June 2013. The researchers used content analysis in collecting data for this study.

\section{Presentation of Tables}

A total of 36 samples was collected from Vanguard and The Guardian newspapers for the three-month period under study. The samples were content analysed to ascertain the type of coverage each newspaper devoted to political issues. The collected data were analysed using simple percentage and the results presented in the following tables.

Table 1 shows that Vanguard newspaper published 129 (82\%) political news stories, 20 (13\%) political feature articles, 5 (3\%) political editorials and 3 (2\%) political cartoons, while The Guardian published 96 (89\%) political news stories, 8 (8\%) political features, 3 (3\%) political editorials, and zero political cartoons. The figures show that Vanguard newspaper carried more political matters than The Guardian during the period under study.

Table 2 shows that Vanguard newspaper carried 38 (24\%) political news stories on the front page, 119 (76\%) on the inside pages, and none on the back page, while The Guardian published 30 (28\%) political news stories on the front page, 66 (62\%) on the inside pages, and $11(10 \%)$ on the back page. It is discernable from the figures that Vanguard newspaper carried more political news stories on the front and inside pages, while The Guardian newspaper carried more political stories on the back page.

Table 3 illustrates that Vanguard newspaper published 105 (67\%) political stories in favour of government, 18 (11\%) against the government, and 34 (22\%) neither in favour nor against the government. The Guardian, however, published 69 (64\%) in favour of government, 16 (15\%) against the government, and took a neutral stand on 22 (21\%) stories. Clearly, Vanguard newspaper published more stories in favour of the government than The Guardian.

Table 4 reveals the comparative analysis of the two newspapers, Vanguard published 157 (59.5\%) more political stories. And The Guardian was, however, 85\% on stories concerning Education, Technology and Art.

\section{T-Test Analyses and Results}

Analyses of the data from the two newspapers are done based on sub-headings and they are given as follows:

From Table 5, the analysis shows that the calculated t-value of 19.55 is greater than the tabulated t-value of 1.98 at 0.05 levels of significance for 262 degrees of freedom. This implies that there is a significant difference in political coverage of Vanguard and The Guardian newspapers. This means that though the level of political coverage of the two newspapers is high, there is still a significant difference in the level of political coverage between the two newspapers.

From Table 6, the analysis shows that the calculated t-value of 13.64 is greater than the tabulated t-value of 1.98 at 0.05 levels of significance for 262 degrees of freedom. This implies that there is a significant difference in classification of political news coverage according to story placement between Vanguard and The Guardian newspapers. 
Table 1. Frequency distribution of political coverage of Vanguard and The Guardian newspapers between April 1 and June 30, 2013.

\begin{tabular}{ccc}
\hline Category & & Publications \\
\cline { 2 - 3 } News & Vanguard & The Guardian \\
\cline { 2 - 3 } Features & $129(82 \%)$ & $96(89 \%)$ \\
Editorial & $20(13 \%)$ & $8(8 \%)$ \\
Cartoons & $5(3 \%)$ & $3(3 \%)$ \\
Total & $3(2 \%)$ & $0(0 \%)$ \\
& $157(100 \%)$ & $107(100 \%)$
\end{tabular}

Source: field work 2013.

Table 2. Classification of political news coverage according to story placement.

\begin{tabular}{ccc}
\hline & & \multicolumn{2}{c}{ Publications } \\
Story Placement & Vanguard & The Guardian \\
\cline { 2 - 3 } & $38(24 \%)$ & $30(28 \%)$ \\
Front Page & $119(76 \%)$ & $66(62 \%)$ \\
Inside Page & 0 & $11(10 \%)$ \\
Back Page & $\mathbf{1 5 7}(\mathbf{1 0 0} \%)$ & $\mathbf{1 0 7}(\mathbf{1 0 0 \% )}$ \\
Total & & \\
\hline
\end{tabular}

Source: field work 2013.

Table 3. Classification of political news coverage according to readers’ interest.

\begin{tabular}{ccc}
\hline \multirow{2}{*}{ Readers' Interest } & \multicolumn{2}{c}{ Publications } \\
\cline { 2 - 3 } & Vanguard & The Guardian \\
Favourable & $105(67 \%)$ & $69(64 \%)$ \\
Unfavourable & $18(11 \%)$ & $16(15 \%)$ \\
Neutral & $34(22 \%)$ & $22(21 \%)$ \\
Total & $\mathbf{1 5 7}(\mathbf{1 0 0} \%)$ & $\mathbf{1 0 7} \mathbf{( 1 0 0 \% )}$ \\
\hline
\end{tabular}

Source: field work 2013.

Table 4. Comparative analysis of subject mix in Vanguard and The Guardian newspapers.

\begin{tabular}{cccc}
\hline \multirow{2}{*}{ Subjects Covered } & \multicolumn{2}{c}{ Publications } & \multirow{2}{*}{ Total } \\
\cline { 2 - 3 } & Vanguard & The Guardian & $264(100 \%)$ \\
Government/Politics & $157(59.5 \%)$ & $107(40.5 \%)$ & $103(100 \%)$ \\
Health/welfare & $64(62 \%)$ & $39(38 \%)$ & $722(100 \%)$ \\
Education/Technology/Art & $111(15 \%)$ & $611(85 \%)$ & $817(100 \%)$ \\
Business/Economy & $256(31 \%)$ & $561(69 \%)$ & $68(100 \%)$ \\
Agriculture & $49(72 \%)$ & $19(28 \%)$ & $240(100 \%)$ \\
Crime/Violence & $128(53 \%)$ & $112(47 \%)$ & $47(100 \%)$ \\
Religion/Morality & $8(17 \%)$ & $39(83 \%)$ & $850(100 \%)$ \\
Sports/Entertainment & $193(23 \%)$ & $657(77 \%)$ & $1318(100 \%)$ \\
Others & $485(37 \%)$ & $833(63 \%)$ & \\
\hline
\end{tabular}

Source: field work 2013. 
Table 5. T-test analysis of the differences in political coverage of Vanguard and The Guardian newspapers between April 1 and June 30, 2013.

\begin{tabular}{ccccc}
\hline Group & $\mathrm{N}$ & $\bar{X}$ & t-cal & Decision at $P<0.05$ \\
\hline Vanguard & 157 & 42.2 & 19.55 & NS \\
The Guardian & 107 & 33.6 & & \\
\hline
\end{tabular}

* = Significance at $0.05 ; \mathrm{t} \infty=1.98 ; \mathrm{df}=262 . \mathrm{NS}=$ no significance at 0.05 .

Table 6. T-test analysis of the differences in classification of political news coverage according to story placement between Vanguard and The Guardian newspapers.

\begin{tabular}{ccccc}
\hline Group & $\mathrm{N}$ & $\bar{X}$ & t-cal & Decision at $P<0.05$ \\
\hline Vanguard & 157 & 41.4 & 13.64 & NS \\
The Guardian & 107 & 35.4 & & \\
\hline
\end{tabular}

* $=$ Significance at $0.05 ;$ t $\infty=1.98 ; \mathrm{df}=262$. NS $=$ no significance at 0.05 .

\section{Discussion of Findings}

\subsection{Readers' Interest on Political Coverage in the Two Newspapers for the Three Months Period under Study}

From Table 3, one can easily discern the editorial nuance of Vanguard newspaper towards reporting political issues. Of their 157 published political stories during the period under study, a whopping 105 (67\%) were skewed to favour the government, 34 (22\%) were reported dispassionately; only 18 (11\%) of the lot contradicted government views. Although it would appear that The Guardian published more unfavourable stories-16 (15\%), it, in fact, gave the government a good image by publishing 69 (64\%) in support of the ruling class, while remaining neutral on only 22 (21\%) political stories published during the period under study. The two national dailies, therefore, failed to give comprehensive reportage to political issues. It is likely that these newspapers-though privately owned-relaxed in their watchdog functions and rather became the mouth piece of the government, rather than the voice of the masses.

From the result of the data analyses presented in Table 5 and Table 6, it can be seen that the level of political news coverage of Vanguard and The Guardian is significantly high. The result of these findings is in agreement with Haque cited in Udomisor (2002) who observes that the news media devote a substantial part of their time and resources to covering politics. The result of the findings also correlates with that of Ghorpade (1986) who postulated that the press plays an influential role in a country's political milieu, which is, according to him, why readership of newspapers is known to grow higher during election years and that by emphasizing certain issues over others, the press plays an agenda-setting role among the educated elite in the society. The result of the study also corresponds with Brookfield's (1986) who states that the mass media play a crucial role in framing our views of the world and the context within which we decide which issues and problems are significant in the political realm.

\subsection{Deductions from Level of Prominence Accorded Political Issues in the Selected Newspapers}

Story placement in newspapers confers importance or unimportance in a story, and this can be recognised by readers. According to McCombs and Shaw (1972, 1976), as cited in McQuail and Windahl (1981): Audiences not only learn about issues and matters through the media, they also learn how much importance to attach to an issue or topic from the emphasis the mass media place upon it (p. 62).

In summarizing the data from Table 2, one can estimate how much importance the selected dailies attached to political issues. Vanguard carried 38 (24\%) stories on the front page, 119 (76\%) on the inside pages, and none on the back pages. The fact that they buried more stories on the inside pages, indicates the low level prominence attached to some political issues. The Guardian had more stories on the front and back pages-30 (28\%) and, 11 (10\%) respectively, and published 66 (62\%) on the inside pages. This result shows that by not emphasizing political news through front page placement, the press in Nigeria has not adequately stimulated political con- 
sciousness in the minds of the people and at the same time failed to give prominence to political issues to encourage democracy to take firm root in the country's governance. This might have been the reason for frequent military interference in the democratic process in the past.

\subsection{Assessing the Subject Matrix in Vanguard and The Guardian Newspapers}

From the data in Table 4, it is deducible that the newspapers did not publish heavily on political issues and that even though Vanguard newspaper outranked The Guardian in that regard, the balance is still not tipped in favour of robust political reporting. The data show that political news coverage was not given adequate attention in the two national dailies as only a minor fraction of editorial content was allotted to political issues. And while the researchers recognise that the relative imbalance might be an editorial policy of each medium concerned, it is regrettable that these newspapers published little of the less appealing aspects of governance perhaps due to the strong influence of government on the economic fortunes of these dailies. This situation accounts for the tendency of reporting only what the government would rather have the people know, leaving out the equally crucial but unpopular aspects of governance, thus conjuring a pseudo-partnership between the government and the press. The result of the field study in Table 3 also confirms the finding in Table 2 which shows that the press in Nigeria has not given adequate coverage to political issues and that this has affected the political process in several ways. Because of lack of sufficient coverage of political issues of the press, people are not stimulated to regard political participation as a matter of concern to the citizens. This, therefore, means that the political consciousness among the ordinary citizens is very low which ultimately translates into a weak democratic foundation in the country.

\section{Conclusion}

This study was undertaken to assess the approach to political reporting in two selected national dailies-Vanguard and The Guardian that arguably typify the press in Nigeria. It was discovered that political issues were not robustly reported, or given prominence by way of catchy placement or location in the newspaper, and stories were mostly presented in favour of the government. These, the researchers observed, did little to promote a sound political culture among readers. It also jeopardized the prestige of the press, portraying it as a partner to the government rather than a voice for the people. The press by not giving adequate coverage to political issues has not stimulated political consciousness in Nigeria as it is obtainable in the developed nations of the world. Under this condition, democracy has not taken firm posture in the country as is the case in developing societies where frequent military interventions in politics have become the order of the day, except of recent, due to mostly the Western governments' outcry against military regimes in the governance of developing states.

\section{Recommendations}

The researchers also posited ways through which the situation can be improved, chief among which is an improvement in the ratio of political contents to other subject matters in the newspapers, and also a promotion of objective and balanced reportage. Even though developmental journalism is advocated, there is no excuse to be frivolous with the trust conferred on the media by the citizens. Based on the findings from this study, the researchers found it expedient that the following improvements be made to the current situation in the newspaper sector in Nigeria:

1) Newspaper publishers and operators should ensure that the views and activities of political organisations be fairly represented in their publications even when such associations may hold ideologies that are dissimilar to theirs.

2) Newspaper houses should endeavour to assign journalists to cover and report unbiased political events such as, conventions, campaigns, and elections of every political party in the country.

3) Because the newspaper is a permanent medium, it is very necessary that reporters and editors render vivid and accurate accounts on all events and issues that they put forth for publication.

4) The Nigerian reportorial newspapers, as part of their contributions to promoting and consolidating a sound political culture, should scale-up political proximity in their reportage to encourage effective local content and socio-political participation.

5) While one advocates for contributive knowledge on development-oriented journalism, the reportorial 
newspapers should strive to expose the ills of government and political organisations through investigative reporting rather than reporting only what favours the government.

\section{References}

Berelson, B. (1952). Content Analysis in Communication Research. Michigan: Free Press.

Bledcom (2014). http://www.bledcom.com/uploads/documents/cilliers_steyn_grobler.pdf

Blumler, J. G. \& Gurevitch, M. (1981). Politicians and the Press. In D. Nimmo, \& K. Sanders (Eds.) Handbook of Political Communication (pp. 467-493). Beverly Hills California: Sage Publications.

Brookfield, S. (1986). Media Power and the Development of Media Literature: An Adult Education Interpretation. Harvard Educational Review, 56, 151-168.

Brown, N. J. (2013). A Book: It's Cosmetic and Societal Implications. International Journal of Humanities and Social Science, 3, 47.

Brown, N. J. (2014). Hypothetical Journalism in MACOSA Experience: The Nation and Its Internal Readership Status. International Organisation of Scientific Research, 5, 19.

Coe. (2014). http://www.coe.uga.edu/leap/adminpolicy/dissertations_pdf/2006/osborne_2006_phd.pdf

Daramola, I. (2003). Introduction to Mass Communication (2nd ed.). Lagos: Rothan Press.

Ekwo, U. A. (2014).

http://cmpimedia.org/Wp-content/uploads/2012/07/Tpwards-Africa\%E2\%80\%99s-Renaisssance-Analyzing-the-Influenceof-Media-convergence-on-Democracy-and-Governce-in-Nigeria...pdf

Fico, F. (1984). How Lawmakers Use Reporters: Differences in Specialization and Goals. Journalism Quarterly, 61, 793$800,821$.

Ghorpade, S. (1986). Retrospect and Prospect: The Information Environment and Policy in India. International Communication Gazette, 38, 5-28. http://dx.doi.org/10.1177/001654928603800102

Haque, M. (1986). Is Development News More Salient Than Human Interest Stories in Indian Elite Press? International Communication Gazette, 38, 83-99. http://dx.doi.org/10.1177/001654928603800107

McQuail, D., \& Windahl, S. (1981). Communication Models for the Study of Mass Communication. New York: Longman Group.

NML (2014). http://nml.ru.ac.za/blog/guy-begger/2007/12/05/spot-similarity.html

Sinha, K. A. (1986). Communication and Rural Development: The Indian Scene. International Communication Gazette, 38, 59-70. http://dx.doi.org/10.1177/001654928603800105

Soola, E. O. (1995). Demystifying the Development Process: The Role of Communication in Community Participation for Sustainable Development. Africa Media Review, 9, 16-37.

Udomisor, I. W. (2002). Problems and Prospects of Reporting Conflict in a Democracy: The Editor's Challenge. In U. A. Pate (Ed.), Introduction to Conflict Reporting in Nigeria (pp. 84-98). Lagos: Frankard Publishers.

Udomisor, I. W., \& Bwala, S. J. (2010). Newspaper Coverage of Development and Cultural Issues in Nigeria. The Nigerian Journal of Communication, 8, 25-42.

Uzochukwu, C. E., \& Dunu, I. V. (2010). Socio-Cultural Variables, Audience Perception and Use of Roll-Back Malaria Media Campaigns in South-East Nigeria. The Nigerian Journal of Communication, 8, 67-88.

Wimmer, R. D., \& Dominick, J. R. (2006). Mass Media Research: An Introduction (8th ed.). Belmont, CA: Thomson Wadsworth Publishing. 